\title{
Veículo Autônomo Guiado para Entrega de Máscaras de Proteção no Ambiente Industrial
}

\author{
Adriano Bertoti do Vale1, Dionatan Santana1, Douglas Godoi Ribeiro', Guilherme \\ Stttraube ${ }^{1}$, Sylvio Block ${ }^{1}$, Cassiana Fagundes da Silva ${ }^{1}$ \\ ${ }^{1}$ Faculdade da Indústria - São José dos Pinhais \\ Av. Rui Barbosa, 5881 - Afonso Pena - 83.045-350 - São José dos Pinhais - PR - \\ Brazil \\ \{bertoti86, dionatanhs, douglasgodoy2003, guilherme.gts2303\}@gmail.com, \\ \{sylvio.block, cassiana.silva\}@sistemafiep.org.br
}

\begin{abstract}
In the midst of the Coronavirus pandemic, the World Health Organization has established several recommendations, such as the use of protective masks, to prevent contamination by the virus. In the industrial environment, the replacement of protective masks becomes a complex activity, as the employee cannot always leave the production line. In this sense, this article aims to develop the prototype of an automatically guided vehicle $(A G V)$, in order to bring a solution for the industry to resume activities safely.
\end{abstract}

Resumo. Em meio a pandemia do Coronavírus, a Organização Mundial de Saúde tem estabelecido várias recomendações, como o uso de máscaras de proteção, para a prevenção da contaminação pelo vírus. No ambiente industrial a substituição de máscaras de proteção torna-se uma atividade complexa, pois nem sempre o colaborador pode sair da linha de produção. Nesse sentido, este artigo tem como objetivo desenvolver o protótipo de um veículo guiado automaticamente (AGV), de modo a fornecer uma solução para a indústria retomar às atividades com segurança.

\section{Introdução}

O Ministério da Saúde frente a rápida disseminação do coronavírus no Brasil estabeleceu medidas gerais para diminuir os danos causados pelo vírus a população. Como proteção individual além do distanciamento social, higienização adequada das mãos e superfícies, o uso de máscaras tem sido uma medida recomendada a prevenção da transmissão da doença.

De acordo com a Portaria $\mathrm{N}^{\circ} 1.565$, parágrafo 6.2 de 18 de junho de 2020 do diário oficial da união, faz-se necessário substituir as máscaras de tempos em tempos durante o uso: "6.2. Substituir as máscaras cirúrgicas, a cada quatro horas de uso, ou de tecido, a cada três horas de uso, ou quando estiverem sujas ou úmidas" [Imprensa Nacional, 2020]. Sob essa perspectiva, é recomendável respeitar a duração do tempo de vida útil da máscara para a proteção do indivíduo, seja em público ou em seu ambiente de trabalho. Visando atender as recomendações da Organização Mundial da Saúde (OMS) esse artigo busca desenvolver um protótipo de um robô móvel com um totem integrado para disponibilizar as máscaras em diferentes setores da fábrica. Seu tempo de 
percurso será programado conforme o item 6.2 da portaria $n^{0} 1.565$. De modo que os funcionários devam realizar a troca e descarte de máscaras quando o robô passar pelos pontos de parada.

Diante desse contexto, este artigo apresenta como principal objetivo desenvolver um protótipo de robô no formato AGV (Automated Guided Vehicle) para auxiliar na entrega de máscaras no ambiente industrial. Como objetivos específicos pretende-se: criar um AVG com capacidade para suportar e transportar um dispenser com as máscaras que serão distribuídas; implementar um leitor de RFID anexado ao AGV; dsenvolver um software para registrar todas as leituras feitas via RFID e salvar a matrícula e horário que o colaborador retirou a máscara.; instalar uma placa de rede sem fio no AVG para sincronização de dados; criar um serviço para sincronização de dados coletados no AGV e salvá-los no banco de dados de um servidor.

O artigo está organizado conforme segue. A seção 2 apresenta uma breve descrição sobre os fundamentos dos Veículos Autônomos Guiados (AVGs), bem como do Coronavírus. Na sequência, a seção 3, apresenta os materiais e métodos para o desenvolvimento do protótipo e, por fim, os resultados preliminaries são descritos na seção 4 e as Considerações sobre o trabalho na seção 5.

\section{Revisão da Literatura}

Nessa seção os fundamentos sobre o virus, denominado por Coronavírus, são discutidos, e dos AVGs, bem como destacam-se alguns trabalhos desenvolvidos e aplicados através dos veículos autônomos guiados.

\subsection{Coronavírus}

O Corona vírus é uma família de vírus comum de ser encontrado em animais como, por exemplo gato, camelo, morcegos, entre outras espécies. Raramente houve casos de contaminação entre animais e humanos, porém desde dezembro de 2019 foi registrado o primeiro caso na cidade de Wuhan na China, no qual gerou disseminação da doença devido a transmissão entre as pessoas [Ministério da Saúde, 2020].

A doença causada pelo Corona vírus é denominada COVID-19 e tem aspectos clínicos variando de infecções assintomáticas, quando a pessoa infectada não apresenta sintomas, até casos clínicos graves, que requerem atendimento hospitalar devido à dificuldade respiratória e suporte artificial para respiração. Os primeiros sintomas são muito parecidos com um resfriado, mas que evoluem rapidamente para uma síndrome gripal, com a presença de sintomas característicos como febre, dor de garganta, dor de cabeça, tosse, coriza, dificuldade respiratória, alteração de paladar, podendo chegar até uma pneumonia severa. A transmissão acontece de pessoa doente para outra devido ao contato próximo, através do aperto ou toque de mãos, gotículas de saliva, espirro, tosse, catarro ou objetos infectados que são compartilhados [Ministério da Saúde, 2020].

Algumas recomendações para prevenção da COVID-19 segundo a OMS e o Ministério da Saúde são a utilização de máscaras em todos ambientes em que se mantenha contato com outras pessoas, a realização de troca de máscaras em períodos determinados de acordo com a confecção do seu material. Para máscaras descartáveis e de tecido a sua troca deve ser efetuada a cada quatro horas. Manter uma distância mínima de um metro entre as pessoas em lugares públicos, privados e de convivio social. Ao tossir ou espirrar, cobrir nariz e boca com um lenço de papel e após descartá- 
lo corretamente. Não compartilhar utensílios como copos, talheres, máscaras e outros. Higienizar as mãos frequentemente com água e sabão líquido ou com álcool em gel 70 $\%$.

Por outro lado, em relação ao ambiente de trabalho, as principais recomendações de prevenção da COVID-19 são o incentivo a realização de trabalho em home office. Caso não seja possível essa recomendação deve-se: 1. Manter o ambiente de trabalho limpo e higienizado, evitar ambientes fechados e pouco arejados; 2. Fazer a higienização adequada ao tocar em objetos compartilhados como ferramentas de trabalho; e 3. Identificar os Lixos para descarte de máscaras.

\subsection{Veículos Autônomos Guiadoss}

O Veículo Guiado Automaticamente (AVG) é um meio de transporte automatizado guiado por instruções lógicas para transportar objetos e materiais em indústrias. Dentre as aplicações dessa tecnologia, destacam-se o ramo logístico, principalmente na coleta e transportes de materiais em linha de produção, proporcionando benefícios para empresa, gerando economia de tempo, custo e escopo do projeto [Atlee, 2011].

Considerando uma escala global a utilização dos robôs nas indústrias tem se tornando cada vez mais comum, devido à grande demanda de atividades produtivas e repetitivas, uma vez que essa tecnologia traz maior precisão e, consequentemente, qualidade na concepção e finalização dos produtos desenvolvidos. Segundo Atlee (2011), todo projeto de automação, utiliza robôs que estão em alta em seus seguimentos industriais, dos quais envolvem as linhas montagem, soldagem, pintura, movimentações, entre outras.

Além da área industrial, os AGV's podem ser usados no transporte de malas, pacotes, correspondências em escritórios e empresas. Independente do tipo de sistema adotado, o métodos de desenvolvimento do AVG pode ser escolhidos por laser, por fio e por faixa [Yaghoubi et al, 2012]. Grande parte dos projetos que envolvem o uso de AVG são desenvolvidos, por meio de faixas pretas sobre o chão branco e adotam três sensores de luz e motores $\mathrm{CC}$, sendo que cada motor aciona uma roda do motor e lógica de programação para orientar o mesmo. A lógica de programação em todos projetos pode ser idêntica, sendo assim, o robô segue seu trajeto, como demonstra a Figura 1.

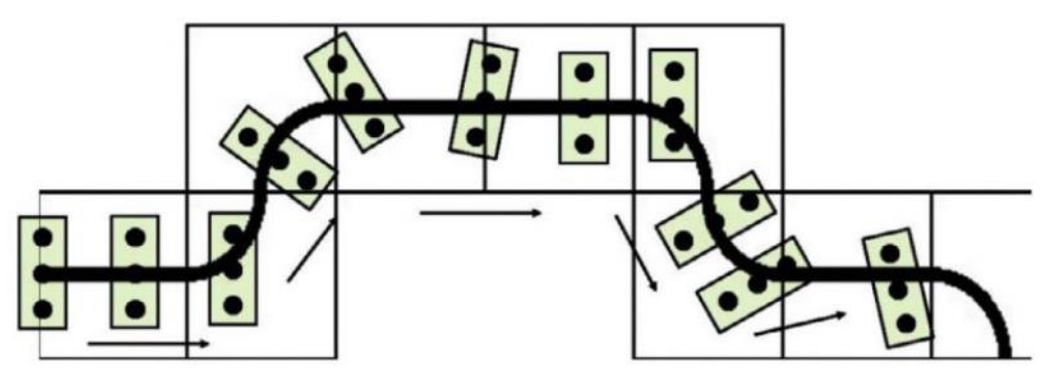

Figura 1. Lógica para Detecção da Linha [Roy et al, 2015, p.2]

Nota-se na imagem, que os sensores são representados pelas bolinhas pretas. Quando a bolinha central encontram-se sobre a linha, e o robô entende que ele deve ser movida para frente, com isso os motores são acionados fazendo todas as rodas se moverem na mesma velocidade. Por outro lado, quando o sensor da esquerda detecta a 
faixa, ele entende que precisa virar para esquerda e manter o percurso, sendo assim, o motor da direita precisa de uma velocidade maior que a da esquerda para que o robô possa virar.

No entanto, quando o sensor da direita encontram a faixa, faz-se necessário virar para direita, logo, o motor da esquerda precisa de velocidade maior que o da direita para que o robô possa virar-se.

\subsection{Trabalhos Relacionados}

$\mathrm{Na}$ literatura encontram-se diversas aplicações de veículos autônomos guiados para auxiliarem na realização de determinado tarefa.

Em Nunes et al (2014) foi desenvolvido um robô AGV, constituído por dois motores CC, treze sensores de luz, um microcontrolador Arduino Uno, uma ponte $\mathrm{H}$ L298N e uma bateria. Baseado neste hardware, o robô foi capaz de seguir a linha branca delimitada em um plano preto. A grande quantidade de pares de sensores de LED emissores e receptores, permitiram maior precisão no reconhecimento da linha. $\mathrm{O}$ Arduino UNO recebeu as informações dos sensores e a partir da programação lógica desenvolvida, acionou a ponte $\mathrm{H}$, ativando na sequência os motores a partir do PWM, onde o microcontrolador não foi capaz de fornecer toda a potência necessária para os motores.

No trabalho desenvolvido por Brito et al. (2020) foi realizado uma análise da produção científica acerca da aplicação do AGV nas diversas áreas da produção industrial publicada em artigos nacionais e internacionais entre 2009 a 2019. Realizouse uma revisão sistemática da literatura, com os artigos pesquisados nas bases de dados ScienceDirect, CAPES, DMPI e Aprepro, a partir dos descritores: Veículo Guiado Automaticamente (AVG), Aplicação do AGV e Utilização do AGV em linha de produção. Amostra constitui-se de 12 artigos. As publicações analisadas descreveram a aplicação do AGV nas diversas áreas da indústria e esse método foi adaptado de acordo com layout da empresa, visando uma melhor movimentação das cargas no interior do ambiente, assim reduzindo os custos e tendo um aumento da eficiência e segurança das atividades. As publicações chamam atenção ainda para o investimento e implantação da automação na indústria, visando à indústria 4.0 almejando a competitividade no mercado.

\section{Materiais e Métodos}

O monitoramento e entrega de máscaras no ambiente industrial será realizado por meio de um AGV que percorre à fábrica através de uma linha no chão da fábrica. O totem é motorizado e contém sensores que permitem que o reconhecimento da linha e que se movimente, por meio dela, até chegar aos pontos estrategicamente marcados.

Toda vez que o sensor encontrar um círculo no chão, o mesmo será parado e o profissional realizará a troca da máscara, aproximando o cartão magnético ou crachá. Será reconhecido que a troca foi efetivada pelo colaborador e na sequência segue sua jornada parando nos pontos demarcados até o final do percurso. Posteriormente, aguardará a próxima etapa para voltar e passar pelo posto de trabalho novamente. Toda a jornada vai ser gravada internamente no totem para ao final do expediente descarregar no sistema interno da indústria. 


\section{Resultados Preliminares}

O protótipo AGV desenvolvido comporta em sua estrutura a etapa de montagem do hardware, que são os componentes físicos acoplados e interligados em um microcontrolador. Para a prototipagem do totem foi utilizado uma caixa de papelão como mostrado na Figura 2(a), podendo agregar os componentes utilizados. Enquanto que na Figura 2(b) para suportar o peso e ter uma melhor tração para os motores, foi utilizado um base de acrílico no fundo da caixa.
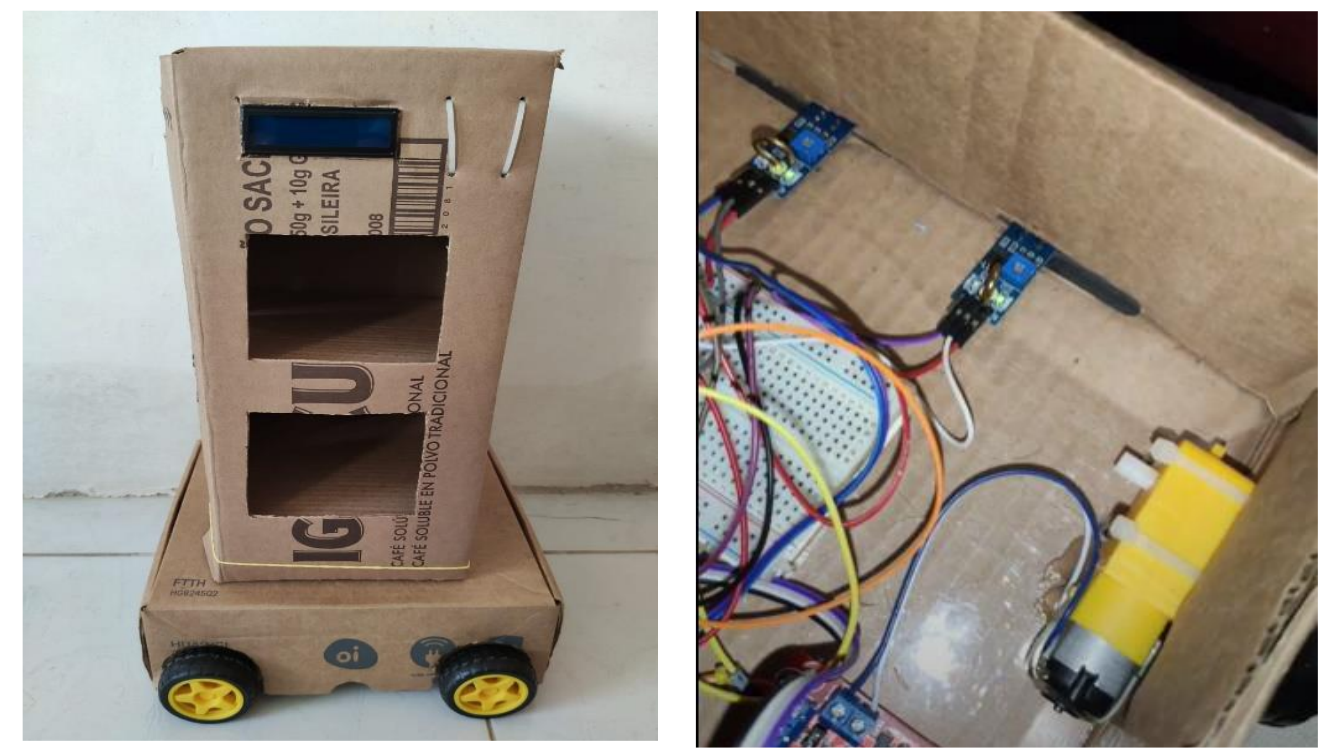

Figura 2. (a) Estrutura Externa; (b) Base de Acrílico

O totem móvel durante seu percurso carrega um dispenser de máscaras e uma lixeira, no momento de registro do usuário com a TAG, de modo a retirar sua máscara e descartar a velha (Figura 3a).
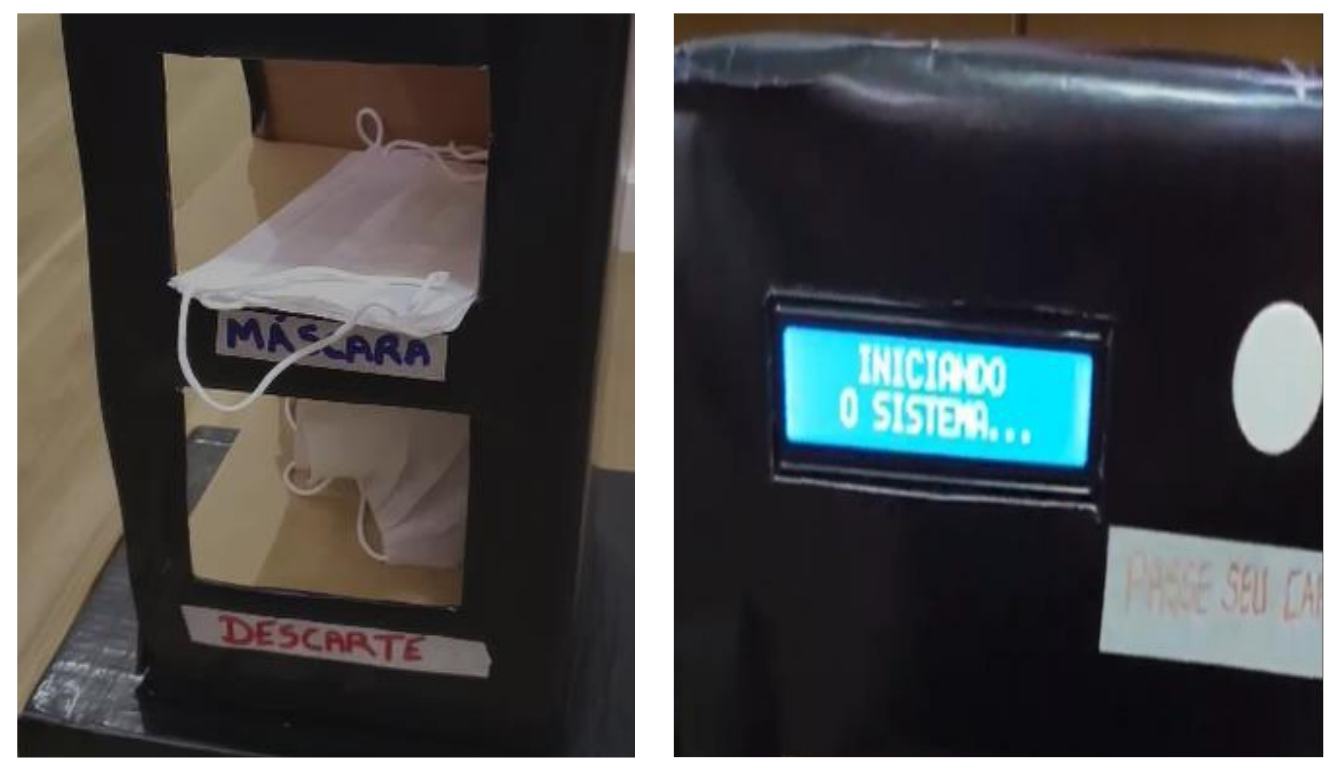

Figura 3. (a) Dispensar de mácara e descarte; (b) LCD do sistema 
Ao ligar o AGV, uma mensagem como demonstrado na Figura 3b, informando que está iniciando o sistema no LCD. Depois de inicializado, o totem permanece parado na base aguardando o tempo programado no "minBase" dentro do banco de dados, mostrando a mensagem no LCD. Após aguardar o tempo na base, o robô sai em busca do próximo posto. Ao encontrar o posto, o LCD informa a posição do posto que está parado e pede a identificação. De posse desta, LCD informa ao funcionário o nome identificado, e por ultimo a mensagem, do LCD informa para retirar a máscara. Para maior entendimento do protótipo desenvolvido e seu funcionamento acesse o link, disponível em https://youtu.be/Gb7KcM3mNk8 .

\section{Considerações Finais}

Este trabalho apresentou como propósito o desenvolvimento de uma solução que auxilie os funcionários de uma indústria na troca de máscaras de proteção. Para isso, a solução proposta deu-se por meio da concepção de um AGV, que por sua vez não causa atraso ou interrupção na linha de produção. Além disso, permite evitar grandes deslocamentos dos funcionários para fazer a substituição e descarte de máscaras de proteção ao vírus.

Após a implementação do projeto inicial, estima-se algumas oportunidades de melhorias no equipamento como, por exemplo, adicionar um mecanismo de dispenser automático, a cada vez que o usuário passar seu cartão de identificação no sensor RFID, disparando um comando para um dispositivo mecânico automatizado. Também, esperase que o dispositivo tenha uso funcional após passar a pandemia de corona vírus quando o uso de máscaras não for mais obrigatório.

\section{Referências}

Atlee, J. (2011). "Selecting safer building products in practice". In: Journal of Cleaner Production, v. 19, pages 459 - 463.

Brito, J.M., Almeida, E.R., Silva, M.P., Santigo, S.B., Junior, A.R.S. (2020). "Aplicação de veículo guiado automaticamente nas diversas áreas de produção da indústria: revisão sistemática da literature”. In: Brazilian Journal of Development, Curitiba, v. 6, n. 2, pages 9486 - 9502.

Impresa Nacional (2020). "Portaria N 1.565, DE 18 DE JUNHO DE 2020”. Disponível em: https://www.in.gov.br/en/web/dou/-/portaria-n-1.565-de-18-de-junho-de-2020262408151 . Acesso em 22 agosto 2020

Ministério da Saúde (2020). "Corona vírus, o que você precisa saber saber". Disponível em: https://coronavirus.saude.gov.br/sobre-a-doenca\#transmissao. Acesso em 22 agosto 2020 .

Nunes, L. F. et al. (2014). "Projeto e Desenvolvimento de um Robô Autônomo Seguidor de Trilha". Universidade Federal de Uberlândia. Uberlândia.

Roy, A., Mithra, M. (2015). "Design of a high-speed line following robot that smoothly follows tight curves" Elsevier, Bangalore, page 16.

Yaghoubi, S. et al. (2012). "Designing and Methodology of Automated Guided Vehicle Robots/Self-Guided Vehicle Systems, Future Trends". International Journal of Research and Reviews in Applied Sciences, Ahar. 